\title{
Investigation and Analysis on Pathogen Distribution of HIV/AIDS Patients with Opportunistic Infection
}

\author{
Lida Mo*, Guosheng Su*, Jiang Lan, Fengyao Wu*, Xiaolu Luo, Hanzhen Su \\ The Fourth People's Hospital Clinical Laboratory Nanning Guangxi, Guangxi Medical University Affiliated to \\ Infectious Diseases Hospital of Nanning, Guangxi AIDS Clinical Treatment Center (Nanning), Nanning, China \\ Email: "wufengyao@126.com
}

Received 24 September 2015; accepted 27 November 2015; published 30 November 2015

Copyright @ 2015 by authors and Scientific Research Publishing Inc.

This work is licensed under the Creative Commons Attribution International License (CC BY). http://creativecommons.org/licenses/by/4.0/

(c) $\underset{\mathrm{EY}}{\mathrm{Y}}$ Open Access

\section{Abstract}

Objective: This study aims to understand the distribution of pathogenic bacteria in the region of HIV/AIDS patients with opportunistic infection. Methods: To count the number of the bacterial culture of HIV/AIDS patients in our hospital from October 2011 to December 2014, and observe the distribution of all kinds of pathogenic bacteria. Results: From the 4269 cases of HIV/AIDS patients' bacteria, 5045 cases were cultured whose main flora distribution was Candida albicans, 1759 cases. The second one was penicillium, 982 cases. The third one was mycobacteria, 557 cases. And then there are 213 cases of Cryptococcus neoformans, 212 cases of Klebsiella pneumonia, 209 cases of $E$. coli, 157 cases of coagulase-negative staphylococci, 112 cases of Candida tropicalis, 90 cases of glabrata, 81 cases of Staphylococcus aureus, 75 cases of Pseudomonas aeruginosa, 60 cases of Salmonella, 48 cases of Acinetobacter and the distribution of the rest of cultured bacterial was less than 40 cases. Conclusion: There are many kinds of types of Pathogenic bacteria in HIV/AIDS patients with the opportunity to infectious. And the majorities are Candida albicans, Penicillium marneffei, Penicillium, Mycobacterium, Cryptococcus neoformans and so on. The infection sites are widely distributed; respiratory and circulatory are the main infected system. Improving the detection rate and reducing the contamination rate can truly reflect the distribution of pathogenic bacteria, and the distribution can guide the infection work in hospital. At the same time, it's good to predict and prevent opportunistic infection. Thus, the patients can get immediate treatment.

\section{Keywords}

HIV/AIDS Patients, Opportunistic Infection, Pathogen, Infection, Distribution

\footnotetext{
*First authors.

\#Corresponding author.
}

How to cite this paper: Mo, L.D., Su, G.S., Lan, J., Wu, F.Y., Luo, X.L. and Su, H.Z. (2015) Investigation and Analysis on Pathogen Distribution of HIV/AIDS Patients with Opportunistic Infection. Advances in Infectious Diseases, 5, 167-173. 


\section{Introduction}

AIDS is a kind of immunodeficiency disease, because HIV attacks body's immune T cells, which makes its function abnormal, and then patients' immune systems will gradually collapse. After that human bodies will become the carrier of various of diseases, resulting in oral fungal infections, tuberculosis, enteritis, encephalitis, sepsis, and a series of overlapping parts, a variety of pathogenic bacteria infections [1]-[6]. In recent years, the distribution of pathogens and drug resistance of opportunistic infections in patients with HIV/AIDS has drawn more and more scholars' attention, but there is no deep and further research for the distribution of the opportunistic infection of AIDS pathogen, especially the distribution of the opportunistic infection of AIDS pathogen in the region. In order to help clinicians with better treatment and prevention of opportunistic pathogen infection, there is a need to understand the distribution of opportunistic infection of pathogenic bacteria in our region. In this research, there are large samples of opportunistic infection of AIDS patients in the region, and some satisfactory results have been achieved. The results of the study are presented as follows.

\section{Materials and Methods}

\subsection{General Materials}

\subsubsection{Objects of the Study}

4269 cases of opportunistic infections in AIDS patients were selected from Guangxi AIDS clinical treatment center in Nanning from October 2011 to December 2014, including 4269 cases of males, 963 cases of women, and they are at the age of 2 to 84 . Their average age was 38.2. All the specimens have been approved by medical ethics commission of AIDS clinical treatment center in Nanning, Guangxi and got consent of the patients themselves for laboratory study.

\subsubsection{Reagents and Instruments}

The reagents and instruments used in this study have passed the quality checks and are approved by the authority of the Department of Clinical Research. Cyclophosphamide instrument are mainly BacT ALTERT 3D120 from BioMerieux. The automatic blood culture instruments are provided by the French BioMerieux Company, and the TIANDIREN TDR-1002 bacteria identification of susceptibility analyzer was provided by Hunan Changsha TIANDIREN Biotechnology Co., Ltd., The carbon dioxide incubator, bacterial culture box, fungal culture curing box and mycobacterial culture box were provided by the Chinese famous brand companies of medical apparatus and instruments. All of Hemoline and the agar plates were provided by Zhengzhou Antu bioengineering Co., Ltd., including the blood agar plate, Jimmy Kang Kai agar, chocolate blood agar, SS agar and CANDIDAID. Neutral Roche culture tube and Mycobacterium drug susceptibility Roche culture tube were provided by Zhuhai Beisuo Biological Technology Co. Ltd... Salmonella serotypes and shigella serotypes were provided by Ningbo Tianrun Biological Pharmaceutical Co., Ltd., Kligler iron agar, nutrient broth agar, and Aupu Toshin paper, bacitracin were supplied by Hangzhou Days and microbial Reagent Co., Ltd. All the reagent kits were provided by Changsha TIANDIREN biotechnology limited company including Enterobacteriaceae kit, non-fermentative bacteria, Staphylococcus aureus kit, Streptococcus kit, Neisseria or Haemophilus kit and yeast like fungus detection kit. All the reagents were used within the period of validity.

\subsection{Methods}

\subsubsection{Culturing Methods}

The culturing processes were operated strictly in accordance with the "national clinical inspection procedures". First of all, inoculate the blood, bone marrow and other body fluids to bacteria to blood culture bottle, and culture the bacteria according to the operating rules on BacT ALERT 3 d120 blood culture instrument. After that, separate different specimens, such as sputum, swabs, lavage and cerebrospinal fluid, urine, and then according to different specimens and culturing purpose, inoculate them selectively on blood plate, macconkey plate, chocolate plate, SS plate, candida color plate, neutral roche culture tube, etc. General bacteria was placed on the temperature box of $35^{\circ} \mathrm{C}$ to $37^{\circ} \mathrm{C}$, from 8 to 72 hours, while fungi specimen were put on the temperature box of $25^{\circ} \mathrm{C}$ to $28^{\circ} \mathrm{C}$, from 2 to 7 days, while mycobacteria was on $37^{\circ} \mathrm{C}$, from 14 to 56 days.

\subsubsection{Bacteria Identification and Judging Criteria}

As for general bacteria, classify them according to the characteristics under colony and observation of gram 
staining microscopic. To begin with, brood this general bacterial on KIA Iron, next coagulate salmonella and shigella with corresponding serotyping, then carry out particular test on part of streptococcus supplemented with the bacteriostasis of barleycourt hin bacteriostatic, CAMP, bile salts lysis, etc. Finally, drug sensitivity of all the cultured bacteria was tested and analyzed further with bacterial identification system of Tenchijin. If there were green or green bacterial colonies on candida color tablet, this kind of bacteria was Candida albicans. If the color was pale blue to iron blue colonies, it is tropical candida, slightly hairy purple colonies, it is soft candida, moist purple it is for smooth candida, white it is for other candida. Those strains and Cryptococcus neoformans on candida color tablet were identified with bacterial identification system of Tenchijin. Some indemnification of bacteria could be observed directly in a microscope without staining, such as penicilliosis marneffei, aspergillus and mucor appraisal. In doing so, there were some features showing in the microscope, like penicillus, spore chains, flask sample capsule, paling small terriers and spherical sporangium, while identified mycobacteria according to the characteristics of roche medium colonies, and confirmed microscopy with acid-fast stain. Then we vaccinated it respectively into roche culture tube with p-nitrobenzoic acid and thiophene-2-carboxylic acid hydrazine to carry out the genus preliminary identification.

\subsubsection{Quality Control}

Strains of Candida albicans (ATCC90028), Candida albicans (ATCC6258), Staphylococcus aureus (ATCC25923), Escherichia coli (ATCC25922), Pseudomonas aeruginosa (ATCC27853) and fecal intestinal bulb (ATCC29212) were provided by the Guangxi clinical test center, while the standard attenuated strain of Mycobacterium tuberculosis (ATCC25177) was provided by Guangxi CDC. The results were strictly acquired through the latest standards of the American clinical laboratory standardization association (CLSI).

\subsubsection{Statistical Data Processing}

The experimental data were entered in the EXCEL form. At the same time, the percentage of the indicators and statistical distribution of pathogen were counted.

\section{Results}

\subsection{The Detection Rate of Different Pathogenic Bacteria}

5045 strains of pathogenic bacteria was isolated from 18,529 specimens (excluding patients with the same specimens of same parts checked out the same strains), the total detection rate was $27.23 \%$. Detection rate from high to low level was arranged in the order: sputum (10.02\%), blood (3.96\%), pharyngeal swab (6.36\%), dejecta (1.66\%), bone marrow $(1.51 \%)$, urine $(0.71 \%)$, cerebrospinal fluid $(0.69 \%)$, pus $(0.61 \%)$, secretions $(0.57 \%)$, abdominal draining $(0.29 \%)$, oral swabs $(0.26 \%)$, lavage $(0.11 \%)$ and drainage liquid $(0.11 \%)$ (Table 1$)$.

\subsection{Distribution of Pathogenic Bacteria}

Among those isolated pathogenic bacteria of 5045 strains, there were 1759 cases of extraction of Candida albicans, accounting for 34.87\%, Carlyle marney penicillium 982 cases, accounting for $19.46 \%$, mycobacteria, 557 cases, accounting for 11.04\%, 213 cases of Cryptococcus neoformans (4.22\%), 212 cases of Klebsiella pneumoniae (4.20\%), 209 cases of E. coli (4.14\%), coagulase negative staphylococcus, 157 cases, accounting for 3.11\%, 112 grams of soft candida, accounting for $2.22 \%, 112$ cases of tropical candida (2.22\%), 90 cases of smooth candida (1.78\%), 81 cases of staphylococcus aureus (1.61\%), 75 cases of pseudomonas aeruginosa $(1.49 \%), 60$ cases of salmonella, (1.19\%), acinetobacter 48 cases, accounted for $0.95 \%$, the rest was less than 40 cases. For more details, please see Table 2 .

\subsection{The Constituent Ratio of General Pathogenic Bacteria in the Infected Parts}

The main candida of Candida albicans in the respiratory tract was $33.88 \%$, gastrointestinal tract $6.26 \%$, and other parts was relative rare, while Carlyle marney fe penicillium in circulation system was $13.41 \%$, joint 3.33\%, respiratory tract $2.34 \%$, and it distributed in other parts. And Mycobacteria in respiratory accounted for $4.56 \%$, circulatory system $2.91 \%$, joint $1.09 \%$, and it distributed in other parts. As for Cryptococcus neoformans, it accounted for $2.14 \%$ in the nervous system and $1.98 \%$ in circulatory system, other parts was relative rare. Other common bacteria mainly distributed in respiratory, circulatory system, skin and soft tissue, urinary tract and joint. For more details, please see Table 3. 
Table 1. The detection rate of different pathogenic bacteria.

\begin{tabular}{cccccc}
\hline The specimen categories & $\begin{array}{c}\text { Number of } \\
\text { specimens } \\
\left(\mathrm{n}_{1}\right)\end{array}$ & $\begin{array}{c}\text { Inspection rate } \\
\left(\mathrm{n}_{1} / \mathrm{N}\right) \%\end{array}$ & $\begin{array}{c}\text { Identification } \\
\text { number }\left(\mathrm{n}_{2}\right)\end{array}$ & $\begin{array}{c}\text { Positive rate } \\
\left(\mathrm{n}_{2} / \mathrm{n}_{1}\right) \%\end{array}$ & $\begin{array}{c}\text { Detection rate } \\
\left(\mathrm{n}_{2} / \mathrm{N}\right) \%\end{array}$ \\
\hline Blood & 7701 & $41.56(7701 / 18,529)$ & 1179 & $15.31(1179 / 7701)$ & $6.36(1179 / 18,529)$ \\
Sputum & 3884 & $20.96(3884 / 18,529)$ & 1889 & $48.64(1889 / 3884)$ & $10.02(1889 / 18,529)$ \\
Pharyngeal swab & 1850 & $9.98(1850 / 18,529)$ & 733 & $39.62(733 / 1850)$ & $3.96(733 / 18,529)$ \\
Cerebrospinal fluid & 1266 & $6.83(1266 / 18,529)$ & 128 & $10.11(128 / 1266)$ & $0.69(128 / 18,529)$ \\
Dejecta & 994 & $5.36(994 / 18,529)$ & 308 & $30.99(308 / 994)$ & $1.66(308 / 18,529)$ \\
Bone marrow & 832 & $4.49(832 / 18,529)$ & 279 & $33.53(279 / 832)$ & $1.51(279 / 18,529)$ \\
Urine & 507 & $2.74(507 / 18,529)$ & 132 & $26.04(132 / 507)$ & $0.71(132 / 18,529)$ \\
Abdominal draining & 494 & $2.67(494 / 18,529)$ & 53 & $10.72(53 / 494)$ & $0.29(53 / 18,529)$ \\
Pus & 314 & $1.69(314 / 18,529)$ & 113 & $35.98(113 / 314)$ & $0.61(113 / 18,529)$ \\
Secretions & 164 & $0.89(164 / 18,529)$ & 106 & $64.63(106 / 164)$ & $0.57(106 / 18,529)$ \\
Lavage & 153 & $0.83(153 / 18,529)$ & 21 & $13.72(21 / 153)$ & $0.11(21 / 18,529)$ \\
Oral swabs & 120 & $0.65(120 / 18,529)$ & 48 & $40.00(48 / 120)$ & $0.26(48 / 18,529)$ \\
Venous conduit & 70 & $0.38(70 / 18,529)$ & 7 & $10.00(7 / 70)$ & $0.04(7 / 18,529)$ \\
Drainage liquid & 62 & $0.33(62 / 18,529)$ & 20 & $32.26(20 / 62)$ & $0.11(20 / 18,529)$ \\
Others & 118 & $0.64(118 / 18,529)$ & 29 & $24.58(29 / 118)$ & $0.16(29 / 18,529)$ \\
Total & 18,529 & 100.00 & 5045 & $27.23(5045 / 18,529)$ & $27.23(5045 / 18,529)$ \\
\hline
\end{tabular}

Table 2. The constituent ratio of 5045 strains of pathogenic bacteria.

\begin{tabular}{|c|c|c|c|c|c|}
\hline \multicolumn{3}{|c|}{$\mathrm{G}+$ aerobic rods $(\mathrm{n}=331)$} & \multicolumn{3}{|c|}{ G+ aerobasilus $(n=591)$} \\
\hline Bacteria & Strains & Constituent ratio (\%) & Bacteria & Strains & $\begin{array}{c}\text { Constituent } \\
\text { ratio (\%) }\end{array}$ \\
\hline $\begin{array}{l}\text { Coagulase negative } \\
\text { staphylococcus }\end{array}$ & 157 & 3.11 & Mycobacterium & 557 & 11.04 \\
\hline Staphylococcus aureus & 81 & 1.61 & Corynebacterium & 13 & 0.26 \\
\hline Enterococcus faecalis & 16 & 0.32 & Rhodococcus equi & 12 & 0.24 \\
\hline Streptococcus sanguis & 16 & 0.32 & Arcanobacterium pyogenes & 2 & 0.04 \\
\hline Others G+ aerobic rods & 61 & 1.21 & Others G+ aerobasilus & 7 & 0.14 \\
\hline \multicolumn{3}{|c|}{$\mathrm{G}-$ aerobic rods $(\mathrm{n}=812)$} & \multicolumn{3}{|c|}{ Fungus $(\mathrm{n}=3311)$} \\
\hline Bacteria & Strains & $\begin{array}{l}\text { Constituent ratio } \\
\text { (\%) }\end{array}$ & Bacteria & Strains & $\begin{array}{l}\text { Constituent } \\
\text { ratio (\%) }\end{array}$ \\
\hline Klebsiella pneumoniae & 212 & 4.21 & Candida albicans & 1759 & 34.87 \\
\hline Escherichia coli & 209 & 4.14 & Penicillium marneffei & 982 & 19.48 \\
\hline Pseudomonas aeruginosa & 75 & 1.49 & Cryptococcus neoformans & 213 & 4.22 \\
\hline Salmonella & 60 & 1.19 & Candida krusei & 112 & 2.22 \\
\hline Acinetobacter & 48 & 0.95 & Candida tropicalis & 112 & 2.22 \\
\hline Enterobacter cloacae & 25 & 0.50 & Candida glabrata & 90 & 1.78 \\
\hline Others G-aerobic rods & 183 & 3.63 & Others fungus & 45 & 0.89 \\
\hline
\end{tabular}


Table 3. The composition of common pathogenic bacteria in the infected parts.

\begin{tabular}{|c|c|c|c|c|c|c|c|c|c|c|}
\hline Pathogens parts & Respiratory & $\begin{array}{l}\text { Circulatory } \\
\text { system }\end{array}$ & $\begin{array}{l}\text { Gastrointestinal } \\
\text { tract }\end{array}$ & Joint & $\begin{array}{l}\text { Skin and } \\
\text { soft tissue }\end{array}$ & $\begin{array}{l}\text { Urinary } \\
\text { tract }\end{array}$ & $\begin{array}{l}\text { The } \\
\text { nervous } \\
\text { system }\end{array}$ & $\begin{array}{l}\text { Serous } \\
\text { cavity }\end{array}$ & Others & Total \\
\hline $\begin{array}{l}\text { Penicillium } \\
\text { marneffei }\end{array}$ & 2.34 & 13.41 & 0.18 & 3.33 & 0.06 & 0.02 & 0.02 & 0.04 & 0.08 & 19.48 \\
\hline $\begin{array}{l}\text { Cryptococcus } \\
\text { neoformans }\end{array}$ & 0.04 & 1.98 & 0.00 & 0.04 & 0.00 & 0.02 & 2.14 & 0.00 & 0.00 & 4.22 \\
\hline Candida albicans & 29.52 & 0.16 & 4.71 & 0.00 & 0.08 & 0.26 & 0.02 & 0.06 & 0.06 & 34.87 \\
\hline G soft candida & 1.55 & 0.00 & 0.54 & 0.00 & 0.04 & 0.04 & 0.00 & 0.00 & 0.06 & 2.22 \\
\hline Tropical candida & 1.60 & 0.00 & 0.46 & 0.00 & 0.04 & 0.06 & 0.00 & 0.00 & 0.06 & 2.22 \\
\hline Candida glabrata & 1.21 & 0.00 & 0.55 & 0.00 & 0.00 & 0.00 & 0.00 & 0.00 & 0.02 & 1.78 \\
\hline Mycobacteria & 4.56 & 2.91 & 0.54 & 1.09 & 0.71 & 0.04 & 0.34 & 0.73 & 0.12 & 11.04 \\
\hline $\begin{array}{c}\text { Klebsiella } \\
\text { pneumoniae }\end{array}$ & 3.39 & 0.14 & 0.00 & 0.02 & 0.32 & 0.32 & 0.00 & 0.00 & 0.02 & 4.21 \\
\hline Escherichia coli & 1.98 & 0.42 & 0.00 & 0.02 & 0.77 & 0.63 & 0.00 & 0.06 & 0.26 & 4.14 \\
\hline $\begin{array}{c}\text { Staphylococcus } \\
\text { aureus }\end{array}$ & 0.24 & 0.65 & 0.00 & 0.06 & 0.61 & 0.00 & 0.00 & 0.00 & 0.06 & 1.61 \\
\hline $\begin{array}{c}\text { Pseudomonas } \\
\text { aeruginosa }\end{array}$ & 1.05 & 0.16 & 0.00 & 0.00 & 0.18 & 0.08 & 0.00 & 0.00 & 0.02 & 1.49 \\
\hline Salmonella & 0.04 & 0.85 & 0.06 & 0.14 & 0.04 & 0.04 & 0.00 & 0.00 & 0.02 & 1.19 \\
\hline Acinetobacter & 0.73 & 0.04 & 0.00 & 0.02 & 0.06 & 0.08 & 0.00 & 0.00 & 0.02 & 0.95 \\
\hline $\begin{array}{l}\text { Coagulase negative } \\
\text { staphylococcus }\end{array}$ & 0.08 & 1.34 & 0.00 & 0.65 & 0.56 & 0.32 & 0.00 & 0.02 & 0.12 & 3.11 \\
\hline Other pathogens & 4.03 & 1.33 & 0.02 & 0.16 & 0.87 & 0.71 & 0.02 & 0.14 & 0.20 & 7.47 \\
\hline Total & 52.36 & 23.38 & 7.06 & 5.53 & 4.34 & 2.62 & 2.54 & 1.05 & 1.12 & 100.00 \\
\hline
\end{tabular}

\section{Discussion}

It happens occasionally that AIDS opportunistic infects with pathogen, which is mainly due to HIV attacks the body's immune system, making patients with low immunity and getting all kinds of opportunistic infections. This study aims to analyze distribution of opportunistic infections in patients with HIV/AIDS pathogen. Great achievement has been made, which will provide a scientific basis for clinical treatment.

This study indicates that different specimens pathogen detection rate of opportunistic infections in patients with HIV/AIDS depends on specimens quantity and the positive rate. Sputum specimen detection rate is the highest, because it is most often occur in the respiratory tract for patients with HIV/AIDS in this region merging of tuberculosis (TB), fungal infections, hospital infectious diseases, etc. Followed by blood samples, the reason is that the region's HIV/AIDS patients with circulatory system are highly susceptible to Carlyle marney fe penicillium (PSM) and mycobacterium disseminated pathogen invasion. And Stool specimen detection rate is relatively higher, because of varieties of causes to diarrhea in the HIV/AIDS patients in this region, in addition to the salmonella and shigella, dysbacteriosis fungal and high mortality rate of mycobacterium, etc. are included. There is relatively low detection rate of some specimens, like cerebrospinal fluid, abdominal draining, venous catheter and lavage fluid specimens, etc. Although these specimens are under low detection rate, they still do much sense to diagnose opportunistic infections, because these specimens are extracted from sterile or deep parts, pathogenic bacteria isolated from them is of important value for diagnosis.

The results also showed that opportunistic infection pathogenic bacteria of patients with HIV/AIDS changes over the difference of geographic region and risk factors, etc. Fungal infection is the most common complication of HIV/AIDS patients the region, while mycobacteria was reported to be the most common one in Dali region by Yin Guangzhi, etc. [1]. And bacteria were thought to be the most common one in Sichuan region by He Chenghua, etc. [2]. The reasons causing theses difference are that wide application of efficient broad-spectrum antibiotics, immunosuppressant, antitumor drugs, thorough development catheter technique and surgical inter- 
ventional therapy were used in this region. Besides, fungal hyphae can be mixed into sclerotium, and cable membrane, stroma and other special structure, which can enhance its breeding, spreading, resistance and create favorable conditions for the deep infection.

Among those bacterial, Candida albicans is preponderant, followed by PSM and Cryptococcus neoformans, while Liang Linhui [3] and Hu Y [4] thought that HIV/AIDS patients with fungal infection in southern China, PSM strains is preponderant. It may be connected with fixed value bacteria and pathogens of syndrome differentiation, quality and quantity of regional samples and so on. The constituent ratio of Mycobacterium reported authoritatively by Liu Jiao, etc. was $14.44 \%$ [5], which was relatively lower than what Zuo Xiaogong reported as $13.76 \%$ [6]. However, it can explain that there are many cases of HIV/AIDS patients co-infected with mycobacterial infection. It is hard to control this situation. Other bacterial infections constitute ratio accounts for $23.43 \%$, which is thought to be concerned with hospital infection by the authors, because the majority of patients with HIV/AIDS in this region have more than 30 days hospitalization time, invasive operation, merger of two or more parts of the opportunistic infection, and less than 200 CD4 cells per microliter risk factors occurs [7]. Staphylococcus aureus, Acinetobacter baumannii, Pseudomonas aeruginosa, Klebsiella pneumoniae, etc. are the main pathogens of nosocomial infection.

\section{Conclusions}

There are many types of pathogen in opportunistic infections patients with HIV/AIDS. The main of them are Candida albicans, Carlyle marney fe penicillium, mycobacteria and Cryptococcus neoformans. The infection sites are widely distributed mainly respiratory and circulatory system. Improving the detection rate and decreasing the rate of pollution can truthfully reflect the distribution of pathogenic bacteria. There is much point in predicting, preventing, early diagnosing and timely treating to HIV/AIDS opportunistic infections if we know multiple parts happen to HIV/AIDS patients of opportunistic infections and a variety of pathogenic bacteria are overlapping infected, and the distribution of pathogenic bacteria of opportunistic infections.

The results of this study suggest that multiple parts happen to HIV/AIDS patients of opportunistic infections and a variety of pathogenic bacteria are overlapping infected. The mainly candida was Candida albicans which is mainly distributed in the respiratory tract, parts of it in the digestive tract, the minority in the urinary tract and skin soft tissue. Candida albicans is the dominating bacteria in oropharyngeal engraftment of region's HIV/ AIDS patients, which is consistent with what Balkhair, et al. reported [8]. That is, there is a close relationship between engraftment of immune status and patients' immunity condition [9]-[11]. PSM mostly distributes in the circulatory system and joint, parts of it in the respiratory tract, enteron. It also distributes in other parts. Many scholars have reported similar results [12] [13]. Mycobacteria mainly distributes in the respiratory and circulatory system, serous cavity, skin and soft tissue and joint. It also distributes in other parts, because HIV/AIDS can be transmitted through the respiratory and gastrointestinal tracts, which determines that the high incidence of HIV/AIDS patients can be extrapulmonary tuberculosis. The constituent ratio reported in Sichuan by He Chenghua et al. was $33.96 \%$ [2], while in this region, it was 60.68\%. Candida, PSM and mycobacterium have characteristic of widely disseminated infection. In order to improve the detection rate, it needs to collect different samples at different positions of the different time, and culture for many times. The distribution of Cryptococcus neoformans concentrates in the central nervous system and circulatory system; other parts are rare. Klebsiella pneumonia, E. coli, Pseudomonas aeruginosa, Acinetobacter and Staphylococcus aureus are mainly distributed in the respiratory tract, parts of the distribution in the circulatory system, urinary tract, skin and soft tissue. Distribution of salmonella is given priority to with circulation system; the digestive tract is rare. It is obvious that the distribution of pathogenic bacteria in this region is in respiratory and circulatory system, followed by the digestive tract and joint, while He Chenghua et al. thought that it is given priority to with the respiratory system and digestive system in Sichuan region [2], and Zuo Xiaogong [6] thought that in southern Anhui, it is given priority to with the digestive system and respiratory system. Therefore, the obvious regional difference causes such different results. It is the PSM in the south that it has great influence on the distribution. In recent years, the deep fungal infections, bacteremia, and TB are the main reasons causing the region's HIV/AIDS patients to have to stay in the hospital. Facing opportunistic infections, before identifying it to be pathogenic bacteria, the clinicians should empirically select antibiotics according to patients' condition and infection sites, and then choose effective antibiotics according to results of culturing the pathogenic bacteria and testing antibiotics sensitivity. On the contrary, blindly and abuse using large doses of antibiotics for a long time can lead to drug resistance of pathogenic bacteria and increase of drug resistance strains. 


\section{Limitations}

There are physiological and biochemical characteristics of diversity, serious injury, package of the infection of pathogenic bacteria in biological membrane. This kind of pathogenic bacteria is hard to culture in the existing conditions in the laboratory. Besides this, there are many limitations affecting the pathogen detection rate and the coincidence rate of clinical and further influencing the objective evaluation of the distribution of pathogenic bacteria, such as poor quality control before test, fixed value bacteria and improper differentiation of pathogens and difficulty to distinguish contaminant microorganism.

\section{Acknowledgements}

This study got much help and support from many departments and individuals, such as the projects of science and technology, and the Guangxi AIDS clinical treatment center (Nanning), and other personnel not involved in this project research, all of them offered a great support and help in this research. Now here, all of members of this research group show our deepest appreciation to them, and wish them good health and everything goes well.

\section{Fund Project}

The fund projects are Nanning Guangxi scientific research and technology development plan (NO. 20143154), the Guangxi Zhuang Autonomous Region health department self-financing research project (NO. Z2014574) and Nanning major projects of science and technology (No. 201109047C).

\section{References}

[1] Yin, G.Z., Su, H.Y., Yang, L., et al. (2015) Yunnan Dali Region Opportunistic Infection of AIDS Patients Clinical Pectrum and Its Relationship with +CD++ 4 Cells. Chin J Prim Med Pharm, 22, 1454-1457.

[2] He, C.H., Zhou, R.F., Liu, D.F., et al. (2014) 1465 Cases of Opportunistic Infection of AIDS Patients in Sichuan Area Analysis. Journal of Chongqing Medical, 43, 592-593.

[3] Liang, L.H. (2012) Fungus Bacteria Distribution and Drug Susceptibility Analysis of AIDS Patients in Guixi Guangxi Region. Guangdong Medicine, 33, 107-108.

[4] Hu, Y., Zhang, J., Li, X., et al. (2013) Penicillium marneffei Infection: An Emerging Disease in Mainland China. Mycopathologla, 175, 57-67. http://dx.doi.org/10.1007/s11046-012-9577-0

[5] Liu, J., Lv, B. and Yan, Y. (2013) China Mycobacterium Tuberculosis and Double HIV Infection Rate Analysis. Chinese Journal Epidemiology, 34, 85-90.

[6] Zuo, X.G., Jiang, Y.W., Chen, J., et al. (2014) 109 Cases Hospitalized Patients with HIV/AIDS Clinical and Laboratory Characteristics. Journal of Anhui Medical College, 33, 137-139.

[7] Wu, Y.H. and Guo, S. (2011) Investigation and Analysis of 93 Cases of Deaths from Hospital Infection. Chinese Journal of Hospital Infection, 24, 4251-4253.

[8] Balkhair, A.A., Al-Muharrmi, Z.K., Ganguly, S. and Al-Jabri, A.A. (2012) Spectrum of AIDS Defining Opportunistic Infections in a Series of 77 Hospitalised HIV-Infected Omani Patients. Sultan Qaboos University Medical Journal, 12, 442-448. http://dx.doi.org/10.12816/0003169

[9] Patton, L.L., Ramirez-Amador, V., Anaya-Saavedra, G., Nittayananta, W., Carrozzo, M. and Ranganathan, K. (2013) Urban Legends Series: Oral Manifestations of HIV Infection. Oral Diseases, 19, 533-550. http://dx.doi.org/10.1111/odi.12103

[10] Fu, Q., Xiao, G., Zhao, H.X., et al. (2014) The AIDS Merged Oral Candida 31 Cases of Clinical Analysis. Journal of Practical Oral Medical Journal, 30, 839-841.

[11] Fang, G.L., Zhang, L., Wang, C.S., et al. (2014) HIV/AIDS Patients with Pharyngeal Ulcer Lesions Characteristic Analysis. Chinese Journal of Otolaryngology Head and Neck Surgery, 49, 125-130.

[12] Li, S.C. and Liu, L.J. (2012) HIV/AIDS Patients Blood Culture Result Analysis. Journal of Laboratory Medicine and Clinical, 9, 1656-1657.

[13] Prim, N., López, G., Domínguez, N., Torres, O., Pomar, V. and Sánchez-Reus, F. (2013) Disseminated Penicillium marneffei Infection in an HIV Infected Patient Returning from Vietnam. Revista Clínica Española, 213, e63-e66. http://dx.doi.org/10.1016/j.rce.2013.03.002 